\title{
Judgment of minimal aversion thresholds and tolerance levels in two modalities
}

\author{
RICHARD SULLIVAN, New York University Medical Center, \\ New York, N.Y. I0016 and NORMAN FREIMARK, The City' \\ College of the City Unilersity, New York, N.Y. 10031
}

Eight males and four females judged a minimal aversion threshold (MAT) and a tolerance level for white-noise and electric-shock stimuli. Cross-modal rank correlations of both indgments were found to be significant. Significant sex and practice differences were found for electric-shock judgments but not for white-noise judgments.

Clark \& Bindra (1956) reported significant correlations of pain and tolerance judgments across different techniques of stimulation and attributed their findings to affective rather than cognitive variables. Wolff \& Jarvik (1964) also found significant correlations across certain pain parameter techniques and suggested that such relationships are to be expected when the quality and locus of stimulation is similar. However, it appears possible that other intensive sensory stimuli which are capable of evoking judgments of discomfort, annoyance, and aversiveness would be correlated cross-modally. Melzack \& Casey (1968), for example, have alluded to the possibility that affective responses may be due to the activation of particular central reaction systems regardless of the peripheral mode of stimulation. Woods \& Campbell (1967) have suggested that sensory aversiveness may be related to a common psychological scale. On the assumption that intensive sensory continua may be divided into aversive and nonaversive ranges. several studies have been done to determine a threshold of discomfort or aversion for modalities not usually associated with noxious stimulation. Spieth (1956) obtained judgments of the threshold of annoyance for differing bands of white noise and Sullivan (in press, a) had Ss judge a minimial aversion threshold (MAT) of broad-band white noise. Similarly, Bourassa \& Wirtschafer (1966) and Sullivan (in press, b) have reported discomfort and minimal aversion for white light (brightness) stimulation. Blitz \& Dinnerstein (1968) have noted that electric shock stimulation is capable of evoking subjectively different experiences of discomfort and pain. The present study was designed to determine whether an S's judgments of minimal aversion and tolerance would be correlated across white noise (broad band) and electric shock stimulation.

\section{METHOD}

Eight male and four female undergraduates with normal hearing served as Ss. They were told that the experiment dealt with their ability to detect a level of stimulation which was minimally aversive. The minimal aversion threshold (MAT) was defined to the $S s$ as that level of stimulation which the $S$ experienced as being at the point of becoming annoying. bothersome, and just noticeably aversive. Ss were also told that they were to judge a tolerance level of stimulation. The tolerance level was defined as the maximum amount of stimulation to which the $S$ was willing to expose himself. In addition and with reference only to the electric shock Ss were asked to judge a pain threshold.

The apparatus consisted of a pair of calibrated earphones in circuit with a noise generator, an amplifier and a series of decade resistors. Electric shock stimulation was provided through use of a Variac and a step-up power transformer. A $270,000-0 h m$ resistor was in series with the output of the transformer which was in circuit with a pair of copper electrodes inserted into jars containing saline solution. The second and fourth fingers of S's preferred hand were placed into the jars. Noise levels were measured through use of a Ballantine VTVM and shock levels were measured through use of the VTVM and an ammeter. The range of stimulation used for white noise was $40-122 \mathrm{~dB}$ (re: $.0002 \mathrm{dynes} / \mathrm{cm}^{2}$ ) and for electric shock was $0.8-1.5 \mathrm{~mA}$. All testing was done while Ss were seated in a darkened, sound-attenuated cubicle.

\section{PROCEDURE}

After the Ss received the instructions and definitions they were seated in the cubicle and given a number of practice trials. The Ss were told to say "MAT" into a microphone when the stimulus level was at the point of minimal aversion and "Stop" when the tolerance level had been attained. For the electric shock trials, they were instructed to say "Pain" when they experienced that level of stimulation. Since electric shock is difficult to present in a descending series and previous work ${ }^{l}$ has demonstrated significant differences between ascending and descending MAT judgments of white noise. both forms of stimulation were presented continuously in an ascending series for either a 2-min or 90-sec interval.

The Ss were seen on two separate occasions with an interval of a week to 10 days intervening. The electric-shock and white-noise presentations were randomized and balanced so that half the total number of trials were given during the first session and half on the second occasion. Each $S$ judged the electric shock and white noise twice on each occasion.

\section{RESULTS AND DISCUSSION}

Mean judgments for the four trials for both forms of stimulation were computed and ranked. The rank (Rho) correlation between MAT judgments of electric shock and white noise was $0.76[\mathrm{t}(10)=3.69, \mathrm{p}<.01]$. The ranking of tolerance judgments obtained an $r$ (Rho) of 0.75 $[\mathrm{t}(10)=3.58, \mathrm{p}<.01]$. Sex differences in the judgment of MAT and stop levels were found to be significant only in the judgment of electric shock $(t=2.37, p<.05: t=2.81$, $\mathrm{p}<.02$, respectively). The difference in degree to which MAT and stop judgments varied is suggested by the coefficients of variance which were 25.2 and 35.5 , respectively, for electric shock, and 9.5 and 6.7 , respectively, for white noise.

The overall mean MAT judgment for noise was $82.2 \mathrm{~dB}$ which is close to the value reported for MAT judgments under similar conditions using relatively low adapting noise. ${ }^{1}$ The overall mean judgment of noise tolerance was 103.2 dB which is approximately $20 \mathrm{~dB}$ below the auditory pain threshold reported by Plutchik (1963). The present range of tole rance judgments more closely approximates Plutchik's range of "unpleasantness" thresholds. While the methods of obtaining judgments differed it would appear that the major reason for the difference was the instructions given to the Ss. Blitz \& Dinnerstein (1968) have reported similar differences occurring through use of different types of instructions in the judgment of pain. Their noting that Ss may distinguish discomfort thresholds from pain thresholds was confirmed in the present study where the difference between MAT and pain judgments of electric shock were found to be significant $(t=3.17$, $\mathrm{p}<.01)$. In every instance the MAT judgment was below the pain judgment. Such a distinction may be important to maintain if common psychological scales of aversiveness are to be established across different sensory modes. For example. high amplitudes of loudness and brightness are experienced as being aversive well below the level at which the stimulation gives rise to the experience of sensory pain. Furthermore. the receptor mechanisms which give rise to the experience of pain in these modalities are likely to be different from those which 
give rise to averting, discomforting, and annoyance responses. The experience of sensory pain resulting from overloading the visual or auditory system is most probably due to mechanical changes occurring in the muscles which control the iris or the musculature of the middle ear. Consequently, the pain resulting from these changes is not directly applicable to the effects of overloading the optic or auditory system. Even in those situations where the stimulation does evoke the experience of pain (e.g. radiant heat) the distinction between pain and aversiveness must be made for the $S$. The naive $S$, when given the task of detecting an absolute threshold of pain, assumes that the threshold experience must be aversive. However, with radiant-heat stimulation it would appear likely that the aversion threshold would be above the pain threshold. In most experiments on radiant-heat pain threshold detection the distinction between aversive and pain levels is assumedly enhanced by practice.

In the present study. Ss demonstrated significant changes in judgment of the MAT of electric shock between first and second sessions [Session $X$ : Ss' analysis of variance, $F(1,11)=6.89, p<.01\}$. However, no such differences were found in the judgment of white noise (Sessions X: Ss' analysis of variance, $F(1,11)=2.21, p>.101$. A possible reason for this finding is that $S$ 's previous experience with electric shock has usually been painful. Consequently, Ss are not practiced in judging various degrees of the aversiveness of electric shock stimuli. Similarly, in their judgment of pain their previous experience has led them to equate pain detection with aversiveness. In contrast, most Ss have had sufficient experience in judging various degrees of the aversiveness of noise without equating such judgments with pain.

The relative agreement across studies regarding the aversive, annoyance, and discomfort threshold of white noise (e.g., Laird \& Coyle, 1929; Spieth, 1956; Sullivan, in press, a) suggests that there may be physiological cues present when Ss make their judgments. However, when judgments of aversive sensory stimuli are accompanied by threat or fear these intrusive affective states may void the use of criteria based on physiological cues. The attempt to establish a common scale of sensory aversiveness (Woods \& Campbell, 1967) and to relate the scale to the reactive components of a common neurophysiological system (Melzack \& Casey, 1968) would have to account for and distinguish between affective changes related to sensory intensity and affective changes related to S's fear of the stimulus. Dillon's (1968) tecent woik witit radiant-heat pain judgrrents suzgests the possibility of a constant relationship beiween genaral affective states and it: judgment of the aversiveness of sensory stimulation. From Dillon's findings it appears that even after repeated trials Ss can be grouped according to their responsiveness to pain stimuli (e.g., hypo- and hyperreactive). The affective states of fear or anxiety generated by overloading of sensory systems may be directly related to the individual's capacity to accommodate sensory stimulation. Thus, correlation of aversive judgments would be expected over different sensory systems. Petrie's (1960) claim that an S's reaction to pain stimuli may be predicted on the basis of his augmenting or reducing the effect of other kinds of sensory stimuli would appear to be based on a similar assumption.

\section{REFERENCES}

BLITZ, B., \& DINNERSTEIN, A. Effects of different types of instructions on pain parameters. Joumal of Abnormal Psychology, 1968, 73, 276-280.

BOURASSA, C. M., WIRTSCHAFER, J. D. Mechanism of binocular increase of discomfort to high luminance. Nature, 1966, 212, 1503-1504.

CLARK, J. W. \& BINDRA, D. Individual differences in pain thresholds. Canadian Jourmal of Psychology, 1956, 10,69-76.

DILLON, D. Stimulus intensity, site of stimulation, and individual reactivity as determinants of the energy threshold for pricking pain. Joumal of Experimental Psychology, 1968, 77, 559-566.

LAIRD, D. A., \& COYLE, K. Psychological measurements of annoy ance as related to pitch and loudness. Joumal of the Acoustical Society of America, 1929, 1, 158-159.

MELZACK, R., \& CASEY, K. L. Sensory, motivational and central control determinants of pain. In D. N. Kenshalo (Ed.), The skin senses. Springfield, Ill.: Charles C Thomas, 1968. Chap. 20.

PETRIE, A. Some psychological aspects of pain and the relief of suffering. Annals of the New York Academy of Sciences, 1960, 86, 13-27.

PLUTCHIK, R. Auditory pain thresholds for intermittent, "beat" and steady signals. Perceptual \& Motor Skills, 1963, 16, 863-870.

SPIETH, W. Annoyance threshold judgments of bands of white noise. Journal of the Acoustical Society of America, 1956, 28, 872-877.

SULLIVAN, R. Subjective matching of anxiety to intensities of white noise. Joumal of Abnormal Psychology, in press, a.

SULLIVAN, R. Minimal aversion thresholds for brightness under light and dark adaptation conditions. American Journal of Psychology, in press, $b$.

WOLFF, B. B., \& JARVIK, M. E. Relationship between superficial and deep somatic thresholds of pain with a note on handedness. American Journal of Psychology, 1964, 77, 589-599.

WOOUS, P. J., \& CAMPBELL, B. A. Relative aversiveness of white noise and cold water. Joumal of Comparative \& Physiological Psychology, $1957,64,493-495$.

\section{NOTE}

1. Sultian, R., Waten, R., \& Dabice, M. Effects of adaptation on $1:$ dgrnents of the minimal aversion threshold of white noise. Submitted or putheation, i 968. 